\title{
In vitro and in vivo studies of surface-structured implants for bone formation
}

This article was published in the following Dove Press journal:

International Journal of Nanomedicine

10 September 2012

Number of times this article has been viewed

\section{Lu Xia ${ }^{1,2}$ \\ Bo Feng' \\ Peizhi Wang ${ }^{2}$ \\ Siyang Ding ${ }^{2}$ \\ Zhiyuan Liu' \\ Jie Zhou' \\ Rong Yu'}

'Key Laboratory of Advanced Technologies of Materials, Ministry

of Education, School of Materials Science and Engineering, Southwest Jiaotong University, Chengdu, Sichuan; ${ }^{2}$ Research Institute of Stomatology, Nanjing Medical University,

Nanjing, Jiangsu, China
Correspondence: Bo Feng Key Laboratory of Advanced Technologies of Materials, Ministry of Education, School of Materials Science and Engineering, Southwest Jiaotong University, Chengdu 61003I, People's Republic of China

Tel +86028 87634023

Fax +860288760 I37I

Email fengbo@swjtu.edu.cn
Background and methods: Micronanoscale topologies play an important role in implant osteointegration and determine the success of an implant. We investigated the effect of three different implant surface topologies on osteoblast response and bone regeneration. In this study, implants with nanotubes and micropores were used, and implants with flat surfaces were used as the control group.

Results: Our in vitro studies showed that the nanostructured topologies improved the proliferation, differentiation, and development of the osteoblastic phenotype. Histological analysis further revealed that the nanotopology increased cell aggregation at the implant-tissue interfaces and enhanced bone-forming ability. Pushout testing indicated that the nanostructured topology greatly increased the bone-implant interfacial strength within 4 weeks of implantation.

Conclusion: Nanotopography may improve regeneration of bone tissue and shows promise for dental implant applications.

Keywords: osteoblast, osteointegration, titanium, nanostructure, microstructure

\section{Introduction}

Titanium and its alloys are widely used as orthopedic and dental implant materials because of their satisfactory mechanical properties, resistance to corrosion, and biocompability. ${ }^{1,2}$ The initial interaction between an implant and cells plays an important role in bone regeneration and osteointegration. Because pure titanium implants are bioinert to organisms, attempts have been devoted to modify their surface structures to improve the cellular response.

Implants with microporous surfaces have been used in the clinic in recent years. Acid etching and sandblasting techniques are two methods commonly used to fabricate micropores on titanium implant surfaces. Studies have reported that microporous surfaces can increase surface area and hydrophilicity, which benefits protein adsorption and interaction. Titanium implants also have a crucial effect on cell behavior, such as adhesion, proliferation, differentiation, and bone growth in the presence of microporous topologies. ${ }^{2,3}$ In addition, microporous structures enable bone ingrowth, ${ }^{4,5}$ improving interfacial bonding with alveolar bone.

More recent reports have demonstrated that nanostructures can positively modulate cellular reaction and tissue regeneration. ${ }^{67}$ Mature bone has an average inorganic grain size of $20-50 \mathrm{~nm}$, whereas the average inorganic grain size of woven bone is $10-50 \mathrm{~nm}$. It is suggested that cells sense and respond to surface morphology at the nanoscale level. Ordered $\mathrm{TiO}_{2}$ nanotubes on titanium can be achieved by anodization in an electrolyte 
containing hydrofluoric acid. ${ }^{8} \mathrm{TiO}_{2}$ nanotubes have attracted much attention because of their favorable biocompatibility, and simple and reproducible preparation. Previous studies have shown that nanotubes can improve biomimetic apatite precipitation, osteoblast adhesion, cytoskeleton organization, proliferation, and phenotypic expression. ${ }^{9,10}$ These research findings indicate that modification of titanium implants using nanotubes may be a promising way of achieving faster osteointegration.

In this work, we compared three kinds of surfaces with different structures, ie, nanostructured, microstructured, and flat titanium surfaces. We evaluated the effects of structured titanium on cellular behavior and then verified the cellular response using in vivo studies. Finally, the direct effects of structured surfaces on osteointegration were investigated by interfacial bonding strength testing.

\section{Materials and methods Specimen preparation}

Different topologies of titanium plates were fabricated by mechanical, chemical, and anodization methods. Titanium plates $10 \mathrm{~mm}$ in diameter and $1 \mathrm{~mm}$ in thickness were mechanically polished by 1200-grit SiC sandpaper and chemically polished by mixed $\mathrm{H}_{3} \mathrm{PO}_{4}$ and hydrofluoric acid solutions. $\mathrm{TiO}_{2}$ nanotube layers with an average diameter of $100 \mathrm{~nm}$ were achieved by anodization in an aqueous solution of hydrofluoric acid at a constant voltage of $20 \mathrm{~V}$ for 2 hours at room temperature. Microporous titanium was attained by immersing titanium in an aqueous solution of $\mathrm{HCl}$ and $\mathrm{CaCl}_{2}$ with a molar ratio of $7: 1$ at $60^{\circ} \mathrm{C}$ for 24 hours. Polished titanium plates were used as the control group. After treatment, all of the specimens were washed in acetone and deionized water in an ultrasonic cleaner and dried.

\section{Cell culture}

The MG63 cells used in this experiment were from a lineage derived from a human osteosarcoma. The cells were purchased from the Cell Bank, Chinese Academy of Sciences, Beijing, China. The cells were grown in Dulbecco's Modified Eagle Medium (Gibco, Grand Island, NY) supplemented with penicillin $100 \mathrm{U} / \mathrm{mL}$, streptomycin $100 \mu \mathrm{g} / \mathrm{mL}$, and $10 \%$ fetal bovine serum (Gibco) and cultured in tissue culture polystyrene bottles in an incubator at $37^{\circ} \mathrm{C}$ with $5 \%$ $\mathrm{CO}_{2}$ and $100 \%$ humidity. The culture medium was refreshed every 3 days. When the cells reached confluence, they were subcultured on structured titanium plates at a density of 5000 cells $/ \mathrm{cm}^{2}$.

\section{Cell proliferation}

Cell proliferation was investigated after culture periods of one, four, and seven days using the commercially available 3-(4,5-dimethylthiazol-2-yl)-2,5-diphenyltetrazolium bromide (MTT) assay (Sigma, St Louis, MO). In the MTT assay, mitochondrial dehydrogenases of viable cells cleave the tetrazolium ring of the substrate to yield purple formazan crystals. The resulting purple solution was spectrophotometrically measured at $570 \mathrm{~nm}$ using a spectrophotometer.

\section{Alkaline phosphatase activity}

After culture periods of four and seven days, alkaline phosphatase activity was measured to characterize the normal osteoblast phenotypic response. Adherent cells on the titanium plates were lysed with $2 \mathrm{~mL} / \mathrm{L}$ Triton X-100 (Sinopharm Chemical Reagent Co, Ltd, Shanghai, China) to release intracellular alkaline phosphatase. The lysed solution was incubated with $500 \mu \mathrm{L}$ of alkaline phosphatase substrate solution for 0.5 hours at $37^{\circ} \mathrm{C}$. The reaction was terminated by addition of $250 \mu \mathrm{L}$ of $0.2 \mathrm{~mol} / \mathrm{L} \mathrm{NaOH}$. A colorimetric assay was used to measure the absorbance of solution at $405 \mathrm{~nm}$. Alkaline phosphatase activity was normalized by total protein content.

\section{Western blot analysis}

The MG63 cells were trypsinized after seven days in culture. The collected cell pellets were lysed in a $1 \%$ Triton $\mathrm{X}-100$ solution in the presence of protease inhibitors at $4^{\circ} \mathrm{C}$ overnight. The total protein concentration was measured using a Coomassie blue assay. Thirty micrograms of protein was fractionated by sodium dodecyl sulfate-polyacrylamide gel electrophoresis on a $7 \%$ gel and electrotransferred to nitrocellulose paper (Millipore Corporation, Bedford, MA). Nonspecific protein-protein interactions were minimized by incubation of the blot with $5 \%$ skim milk in $0.5 \%$ Tween 20 -Tris buffered saline solution for 2 hours. The blots were incubated with polyclonal or monoclonal antibodies specific to core-binding factor alpha 1 (Cbfal), osteocalcin, osteoprotegerin, or collagen I (Abcam, Cambridge, MA) for two hours. The blots were then washed, blocked, and developed with peroxidase-conjugated Ig antibody (Wuhan Boster Biological Engineering Co, Ltd, Wuhan Hubei, China).

\section{Implant insertion}

Fifty-four structured implants $(\Phi 3 \times 5 \mathrm{~mm})$ were prepared as described above. Eighteen adult male New Zealand white rabbits were used in the present study. Each group involved 18 implants for in vivo studies. The rabbits were anesthetized 
by intramuscular injection of sodium pentobarbital (Beijing Chemical Reagent Company, Beijing, China) at a dose of $30 \mathrm{mg}$ per $\mathrm{kg}$ body weight. The skin of the rabbits was shaved to provide a surgical field and sterilized with $2 \%$ iodine prior to surgery. Incisions $1.5 \mathrm{~cm}$ in length were made on the medial-proximal surface of the tibia below the knee. A slow-speed handpiece with a drill $3 \mathrm{~mm}$ in diameter and saline cooling was used to make subperiosteal holes in the bone marrow in the tibial metaphysis. Each animal received three different structured implants at the same time. Two implants were placed in one tibia and the other implant was placed in the other tibia. After the implants were inserted into the holes, primary closure was achieved for each animal by suturing. All of the rabbits recovered from surgery and displayed normal mobility and activity after one or two hours. The animals were sacrificed with an overdose of $10 \mathrm{~mL}$ of sodium pentobarbital $100 \mathrm{mg} / \mathrm{mL}$ after two, four, and 12 weeks.

\section{Histomorphometry and immunohistochemical analyses}

The rabbit tibiae were removed and cleaned of soft tissue after implantation for two weeks. The specimens were fixed by soaking in $10 \%$ phosphate-buffered paraformaldehyde for 24 hours. The specimens were decalcified by immersion in ethylenediamine tetra-acetic acid solution for two months and embedded in paraffin. Tissue sections $(4-5 \mu \mathrm{m})$ from paraffin blocks were deparaffinized in xylene and rehydrated with graded alcohols. Thin sections were stained with hematoxylin and eosin, a Masson kit, or immunohistochemistry.

Following the immunohistochemical procedure, the sections were processed by conventional microwave heating in $0.01 \mathrm{M}$ sodium citrate retrieval buffer $(\mathrm{pH}$ 6.0) for 20 minutes to retrieve the antigens. The sections were then incubated with a primary antibody against osteocalcin (mouse monoclonal antibody, ab13418, Abcam) or vascular endothelial growth factor (mouse monoclonal antibody, ab28775, Abcam) for 60 minutes at room temperature and subsequently incubated with goat antimouse EnVision (Dako, Carpinteria, CA) for 30 minutes at room temperature. The reaction product was developed with 3,30-diaminobenzidine and counterstained with hematoxylin. The sections incubated only with conjugated antibody were used as the negative controls.

\section{Interfacial shear strength measurement}

Five rabbits were sacrificed at two, four, and 12 weeks after surgery. The implant sites were exposed, and the bone and soft tissues were carefully removed. The tibiae were cut in half along the longitudinal axis. Subsequently, the implants were pushed out with a universal mechanical testing machine (Instron 5567, Instron, Norwood, MA, Figure 1). The results were recorded by measuring the maximum removal torque at which fracture occurred between the implant and the bone. The ultimate shear strength of the interface $\left(\sigma_{\mathrm{su}}, \mathrm{N} / \mathrm{mm}^{2}\right)$ was calculated by dividing the maximum pushout force by the total bone-implant contact area $(\pi \mathrm{DL})$, where $\mathrm{D}$ is the diameter of the cylindrical implant, and $\mathrm{L}$ is the mean length of bone in contact with the implant at four well defined sites (cranial, caudal, anterior, and posterior of the implant) prior to mechanical testing.

\section{Statistical analysis}

To determine any significant difference between the groups, the data were subjected to a one-way analysis of variance test. Statistical significance was determined at a $95 \%$ confidence level. The average \pm standard error with the sample size ( $\mathrm{n}$ values) is shown in each graph.

\section{Results}

\section{Morphology of titanium surfaces}

The nanotube arrays were aligned on the $\mathrm{TiO}_{2}$ nanotube layer surfaces with a diameter of approximately $100 \mathrm{~nm}$ (Figure 2A). The microporous surface was clearly observed on the microporous titanium surface after acid etching (Figure 2B). The diameters of pores varied between $1 \mu \mathrm{m}$ and $60 \mu \mathrm{m}$ and were mostly in the range of 10-20 $\mu \mathrm{m}$. Many small pores $(1-10 \mu \mathrm{m})$ were distributed on the side walls of large pores $(10-60 \mu \mathrm{m})$ to form a multiscale structure. The surfaces of the polished titanium plates were smooth,

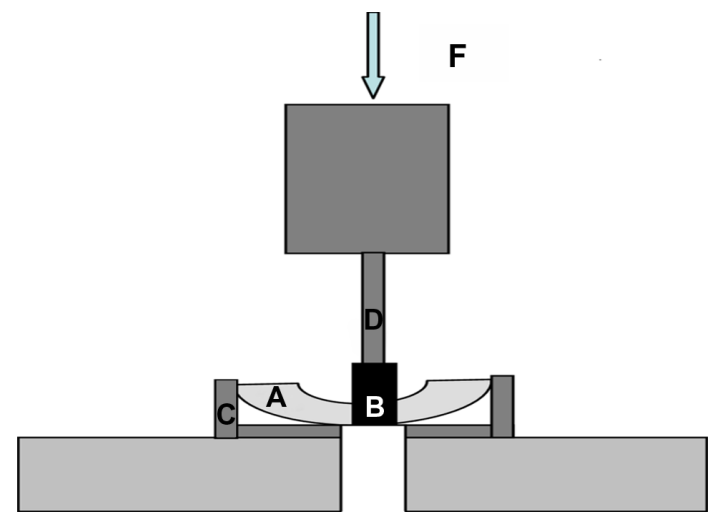

Figure I Schematic diagram of pushout testing. Tibiae were incised into halves (A) to expose the bottom of the implants (B). Tibiae were fixed by an accessorial apparatus $(\mathbf{C})$ and implants were pushed out by the forces $(\mathbf{F})$ loaded using the rod (D) of the mechanical testing machine. 

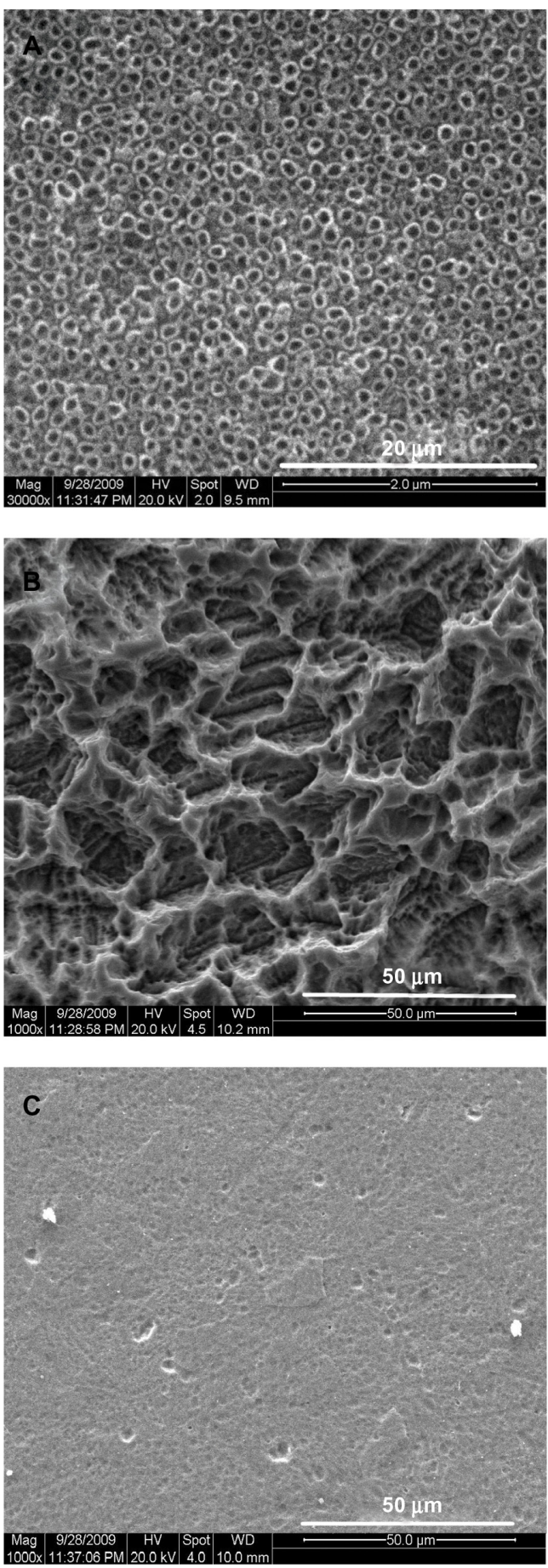

Figure 2 Scanning electron microscopic images of specimens. (A) $\mathrm{TiO}_{2}$ nanotube layer, (B) microporous titanium, and (C) polished titanium plates.

with small shallow pits and grooves generated by the polishing process (Figure 2C).

\section{Cell proliferation}

The $\mathrm{TiO}_{2}$ nanotube layers increased cell proliferation significantly after the first day in culture, while microporous titanium only increased cell proliferation slightly (Figure 3). The optical density values of the $\mathrm{TiO}_{2}$ nanotube layers and microporous titanium were nearly $30 \%$ higher than those of the polished titanium plates after four days in culture. After seven days in culture, apparent differences in optical density values were found between the three structured surfaces. The results showed increased proliferation of osteoblasts cultured on $\mathrm{TiO}_{2}$ nanotube layers compared with that cultured on microporous titanium or polished titanium plates.

\section{Alkaline phosphatase activity}

Cells on $\mathrm{TiO}_{2}$ nanotube layers showed higher alkaline phosphatase levels compared with those on the microporous titanium and polished titanium plate surfaces after four and seven days in culture (Figure 4). There was an approximate $45 \%$ increase in alkaline phosphatase levels on the $\mathrm{TiO}_{2}$ nanotube layers compared with that on polished titanium plates after seven days in culture $(P<0.05)$. Increased alkaline phosphatase was also expressed on microporous titanium in contrast with polished titanium plates at day 7 .

\section{Western blot analysis}

Expression of Cbfal, osteocalcin, osteoprotegerin, and collagen I was determined in cells cultured on the three kinds of surfaces. Western blot analysis showed greater intensities of the immunoreactive protein bands in human osteoblastic cells grown on $\mathrm{TiO}_{2}$ nanotube layers (Figure 5A) compared with those grown on microporous titanium and polished titanium plates. Quantitative densitometry of the Western blots also confirmed higher protein levels for $\mathrm{TiO}_{2}$ nanotube

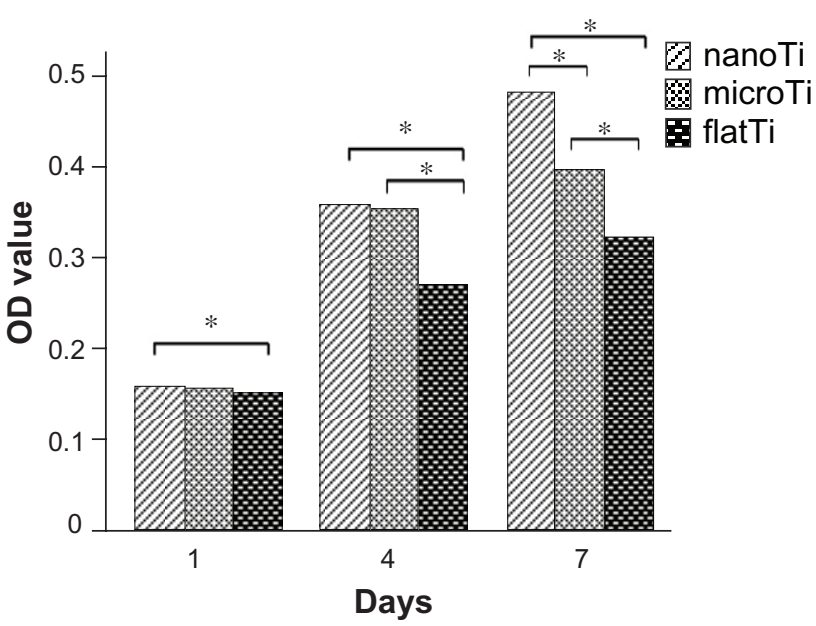

Figure 3 Proliferation of MG63 cells on structured titanium after one, four, and seven days of culture.

Notes: Optical density values of the $\mathrm{TiO}_{2}$ nanotube layers were significantly higher than those of microporous titanium and polished titanium plates after 7 days of culture. $* P<0.05, \mathrm{n}=9$. 


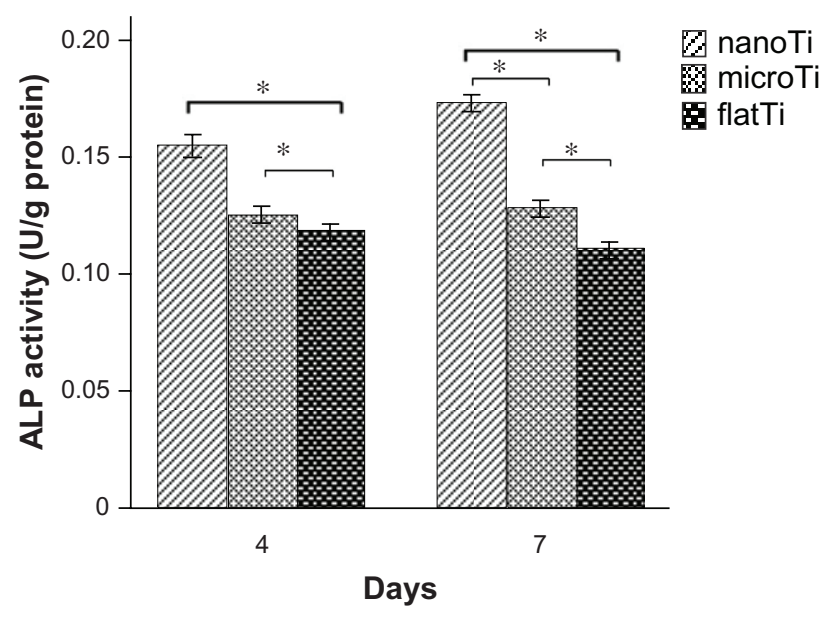

Figure 4 Alkaline phosphatase activity of MG63 cells on structured titanium after four and seven days of incubation.

Notes: Cells on the $\mathrm{TiO}_{2}$ nanotube layers expressed higher alkaline phosphatase activity after four and seven days of culture as compared with microporous titanium and flat titanium plates. More alkaline phosphatase activity was also present on microporous titanium after seven days of culture compared with polished titanium plates. $* \mathrm{P}<0.05, \mathrm{n}=7$.

layers compared with those for microporous titanium, with increased expression of Cbfal (70\%), osteocalcin (40\%), osteoprotegerin (360\%), and collagen I (150\%), as shown in Figure 5B. Moreover, expression of these proteins slightly increased in cells cultured on microporous titanium compared with those cultured on polished titanium plates. Among these proteins, osteocalcin was expressed at higher levels on the titanium plates studied.

\section{Histomorphometry and immunohistochemical analyses}

Compared with microporous titanium (Figure 6 [MHE]) and polished titanium plates (Figure 6 [FHE]), more osteoblasts aggregated on the surface of $\mathrm{TiO}_{2}$ nanotube layers (Figure 6 [NHE]). This result was in accordance with the increased cellular proliferation on the $\mathrm{TiO}_{2}$ nanotube layer specimens observed in the in vitro study. Osteoblasts on the surface of nanostructured implants had abundant cytoplasm, indicating that the osteoblasts were active in synthesis and secretion. To investigate the functional condition of the osteoblasts further, expression of collagen (Figure 6 [FMA, MMA, NMA]) and osteocalcin (Figure 6 [FOC, MOC, NOC]) was examined. Collagen was stained blue in Masson staining. Strong positive staining of collagen (Figure 6 [NMA]) and osteocalcin (Figure 6 [NOC]) was expressed in the $\mathrm{TiO}_{2}$ nanotube layer specimens, which was in line with the results of the in vitro study. In addition, we found high expression of vascular endothelial growth factor and a high degree of capillary formation on the $\mathrm{TiO}_{2}$
A

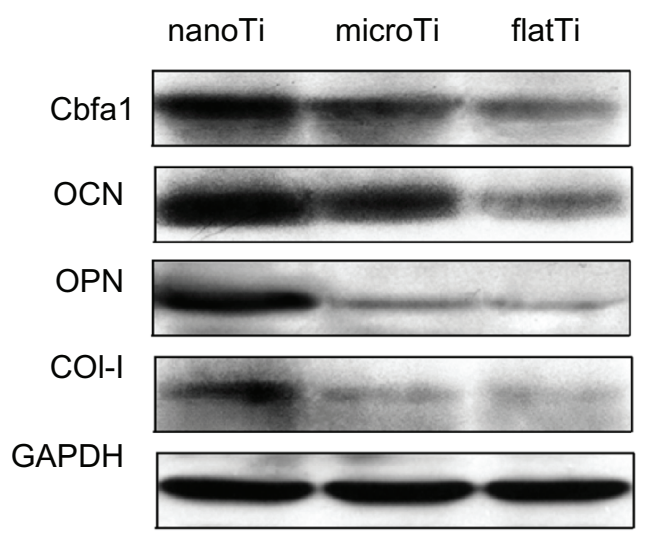

B

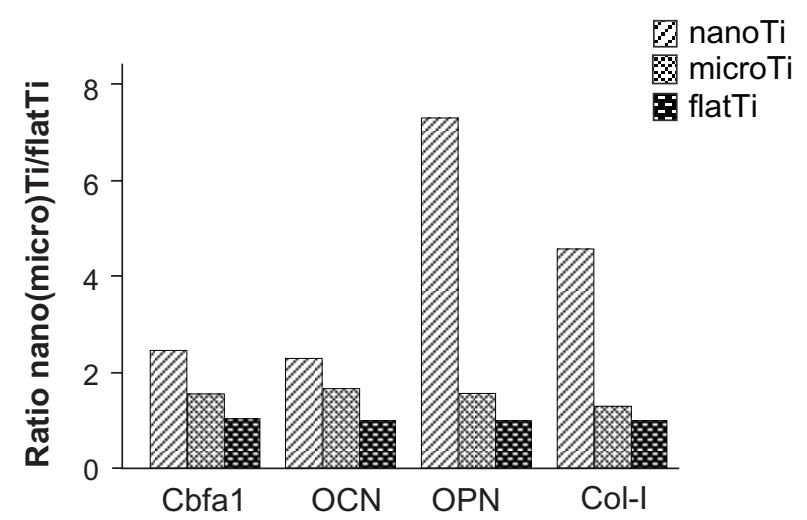

Figure 5 Western blot analysis for the levels of core-binding factor alpha l, osteocalcin, osteoprotegerin, and collagen I in MG63 cells. (A) Immunoreactive bands for above proteins examined on titanium plates with different surfaces. (B) Densitometry analysis for osteoblastic proteins cultured on titanium plates.

Notes: Results are presented as percent increase of band intensity on $\mathrm{TiO}_{2}$ nanotube layers and microporous titanium specimens over flat titanium specimens. Results indicated enhanced expression of Cbfal, osteocalcin, osteoprotegerin, and collagen I in cells cultured on $\mathrm{TiO}_{2}$ nanotube layers than on microporous titanium or flat titanium. Abbreviations: flatTi, flat titanium; nanoTi, $\mathrm{TiO}_{2}$ nanotube layer; microTi, microporous titanium; Cbfal, core-binding factor alpha l; OCN, osteocalcin; OPN, osteoprotegerin; GADPH, glyceraldehyde 3-phosphate dehydrogenase.

nanotube layers and microporous titanium (Figure 6 [NVE] and [MVE]) specimens, which was not present on the polished titanium plate (Figure 6 [FVE]) specimens.

\section{Bone-implant interface strength}

In the early healing period following implantation surgery (2-4 weeks), the $\mathrm{TiO}_{2}$ nanotube layer implants had significantly higher values for maximum pushout force and ultimate shear strength than did the other groups (Table 1). After 12 weeks, no significant difference in ultimate shear strength was found between the experimental groups with different topologies, except for the polished titanium plate implants. Moreover, the maximum pushout forces of all three groups increased significantly between two and four weeks (Figure 7). 

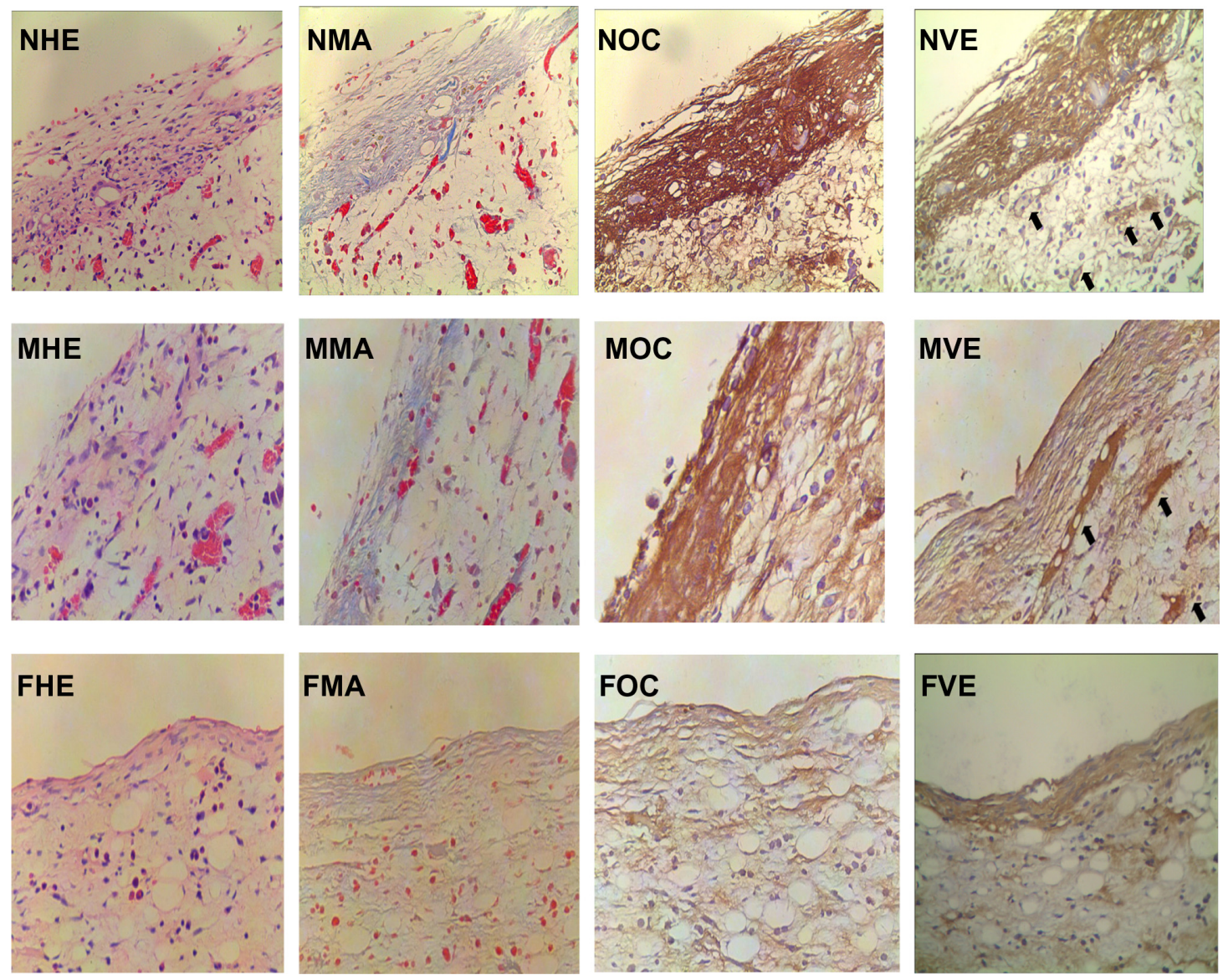

Figure 6 Histomorphometric and immunohistochemical images of peri-implant tissue (400x).

Notes: Osteoblastic cells, collagen, osteocalcin, and vascular endothelial growth factor expression were observed in the $\mathrm{TiO}_{2}$ nanotube layer, microporous titanium, and polished titanium plates. More osteoblasts aggregated at the interface of the $\mathrm{TiO}_{2}$ nanotube layers than on the other two groups. Increased staining of collagen, osteocalcin, and vascular endothelial growth factor (black arrow) were observed in $\mathrm{TiO}_{2}$ nanotube layer specimens at 2 weeks. $\mathrm{NHE}$, MHE, and $\mathrm{FHE}$ : osteoblastic cells stained by hematoxylin and eosin on the $\mathrm{TiO}_{2}$ nanotube layer, microporous titanium, and flat titanium specimens. NMA, MMA, and FMA: collagen stained by Masson assay on TiO nanotube layer, microporous titanium, and flat titanium specimens. $\mathrm{NOC}, \mathrm{MOC}$, and $\mathrm{FOC}$ : osteocalcin expressed on $\mathrm{TiO}_{2}$ nanotube layer, microporous titanium, and flat titanium specimens. NVE, MVE, and FVE: vascular endothelial growth factor expressed on $\mathrm{TiO}_{2}$ nanotube layer, microporous titanium, and flat titanium specimens.

\section{Discussion}

Previous results have indicated that structured implants could improve osteoblastic function and bone formation. Therefore, we investigated the effect of nanoscaled and microscaled implants on osteogenesis. Our results indicate that nanotube surfaces can enhance cell proliferation and lead to a higher level of alkaline phosphatase activity compared with microstructured surfaces. Osteoblasts cultured on nanotube surfaces also exhibited upregulated levels of Cbfal, osteocalcin, osteoprotegerin, and collagen I. Both nanostructured and microstructured implants enhanced expression of vascular endothelial growth factor and increased the formation of capillaries in peri-implant tissues. The ultimate shear strength of the nanostructured implants was significantly boosted within four weeks of in vivo implantation.
It was shown that stimulation of cell growth was greater when the cells were cultivated on nanostructured titanium. Osteoblasts were reported to respond to nanoscale roughness, with a greater cell thickness ${ }^{11}$ due to a larger number of particle binding sites. ${ }^{12}$ It was demonstrated that nanostructured surfaces induced superhydrophilicity of samples. ${ }^{13,14}$ Recent reports indicated that hydrophilic surfaces could improve cell attachment and proliferation ${ }^{15,16}$ more than could hydrophobic surfaces. In addition to surface properties, such as contact area and wettability, Feng et a $1^{17}$ confirmed that chemical functional groups were strongly associated with the behavior of osteoblasts. Nanostructured surfaces seem to promote cellular growth and proliferation due to the higher number of hydroxyl groups. ${ }^{17-19}$

We also found that alkaline phosphatase activity and Cbfal, osteocalcin, osteoprotegerin, and collagen I were 
Table I Maximum pushout force and ultimate shear strength $\left(\sigma_{\text {su }}\right)$ of implants

\begin{tabular}{lrrr}
\hline $\begin{array}{l}\text { Implantation } \\
\text { period }\end{array}$ & $\begin{array}{l}\text { nanoTi } \\
(\mathbf{n}=\mathbf{5})\end{array}$ & $\begin{array}{l}\text { microTi } \\
(\mathbf{n}=\mathbf{5})\end{array}$ & \multicolumn{1}{c}{$\begin{array}{l}\text { flatTi } \\
(\mathbf{n}=\mathbf{5})\end{array}$} \\
\hline $\mathbf{2}$ weeks & & & \\
$\mathrm{F}_{\text {max }}(\mathrm{n})$ & $48.6 \pm 6.2$ & $25 \pm 2.9$ & $15.8 \pm 3.2$ \\
$\sigma_{\text {su }}\left(\mathrm{n} / \mathrm{mm}^{2}\right)$ & $4.0 \pm 0.5$ & $2.2 \pm 0.3$ & $1.3 \pm 0.3$ \\
$\mathbf{4}$ weeks & & & \\
$\mathrm{F}_{\text {max }}(\mathrm{n})$ & $54.6 \pm 4.0$ & $39.4 \pm 3.8$ & $19 \pm 3.34$ \\
$\sigma_{\text {su }}\left(\mathrm{n} / \mathrm{mm}^{2}\right)$ & $4.8 \pm 0.4$ & $3.5 \pm 0.3$ & $1.6 \pm 0.3$ \\
$\mathbf{I} \mathbf{2}$ weeks & & & \\
$\mathrm{F}_{\text {max }}(\mathrm{n})$ & $126.2 \pm 8.6$ & $125.4 \pm 9.6$ & $72.4 \pm 5.3$ \\
$\sigma_{\text {su }}\left(\mathrm{n} / \mathrm{mm}^{2}\right)$ & $10.3 \pm 0.7$ & $10.2 \pm 1.8$ & $5.9 \pm 0.4$ \\
\hline
\end{tabular}

Note: Mean value \pm standard deviation.

Abbreviations: flat $\mathrm{Ti}$, flat titanium; $\mathrm{n}$, number; nano $\mathrm{Ti}, \mathrm{TiO}_{2}$ nanotube layer; microTi, microporous titanium.

greater in cells cultivated on $\mathrm{TiO}_{2}$ nanotube layers than for those cultivated on microporous titanium and polished titanium plates. Some previous studies have demonstrated that cellular proliferation and differentiation showed the opposite trend, depending on surface roughness. ${ }^{20,21}$ However, our study revealed both increased proliferation and enhanced differentiation of osteoblasts on $\mathrm{TiO}_{2}$ nanotube layers. Implants modified with nanotubes may not only accelerate speed but may also promote quantity of bone formation, which is beneficial for enhancing osteointegration. This result may be due to the modulated cellular orientation, cell spreading, ${ }^{22,23}$ and increased apatite deposition ${ }^{24-26}$ induced by $\mathrm{TiO}_{2}$ nanotube layer surfaces. It is reasonable to hypothesize that the way

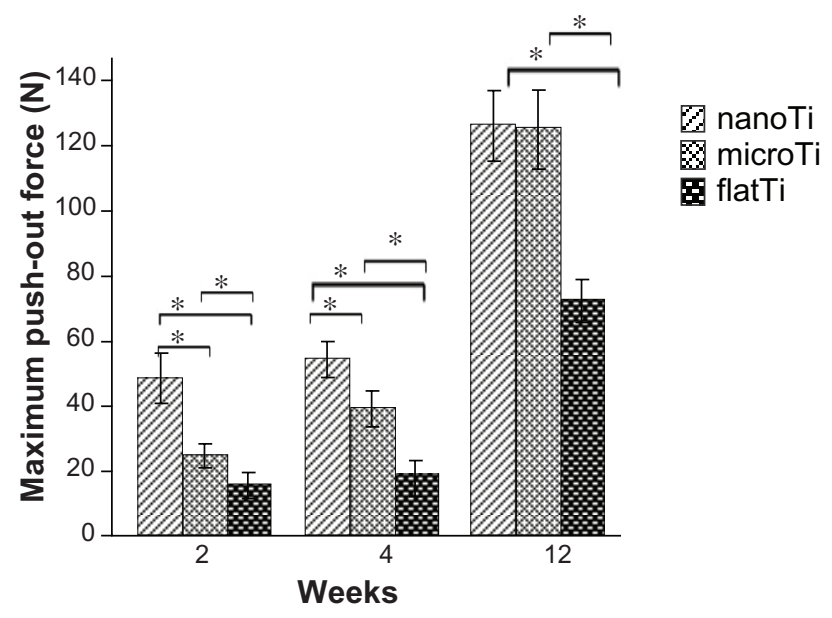

Figure 7 Maximum pushout force of implants measured after two, four, and 12 weeks of implantation.

Notes: The $\mathrm{TiO}_{2}$ nanotube layer implant expressed significantly higher maximum pushout force than microporous titanium and polished titanium plates within four weeks. No significant difference in ultimate shear strength has been shown between $\mathrm{TiO}_{2}$ nanotube layers and microporous titanium at week 12, except for polished titanium plates. $* \mathrm{p}<0.05, \mathrm{n}=5$. in which osteoblasts sense nanostructures is quite different from how they sense microstructures. However, the mechanisms that underlie how nanoscaled surfaces affect osteoblast behavior remain to be determined.

Osteoprotegerin expressed in cells on $\mathrm{TiO}_{2}$ nanotube layers was $360 \%$ higher than that of cells on microporous titanium. Osteoprotegerin suppressed differentiation of osteoclasts and inhibited their activation. ${ }^{27}$ Increased osteoprotegerin levels on $\mathrm{TiO}_{2}$ nanotube layers may suggest that the inhibited activity of osteoclasts may be attributed to successful osteointegration at the bone-nanostructured implant interface.

Histological analysis indicated that more osteoblasts aggregated on the nanostructured titanium surfaces than on the surfaces of the other two groups. Osteoblast proliferation is a prerequisite for bone formation. ${ }^{22} \mathrm{An}$ increased number of cells at the bone-nanostructured implant interface may contribute to the increase in cellular proliferation due to the topology mechanism. These hypotheses were supported by the MTT assay results. The nanostructured titanium surfaces may attract osteoblasts or mesenchymal stem cells due to high affinity and bioactivity ${ }^{9}$ of surfaces. Immunohistochemical analysis also indicated that osteocalcin and collagen proteins were highly expressed on the $\mathrm{TiO}_{2}$ nanotube layer specimens, which confirmed our in vitro study results. Interestingly, the high levels of vascular endothelial growth factor expressed both on the $\mathrm{TiO}_{2}$ nanotube layers and on the microporous titanium specimens were accompanied by a high degree of capillary formation. ${ }^{28}$ Capillaries can deliver sufficient nutrients, which may also contribute to bone regeneration.

Being a more direct and sensitive predictor of implant stability than histomorphometric analysis,$^{29}$ biomechanical testing is utilized to assess implant anchorage in the surrounding bone in implant orthopedics research. ${ }^{30,31} \mathrm{The}^{\mathrm{TiO}_{2}}$ nanotube layers showed a higher value of shear strength than microporous titanium and polished titanium plates four weeks after implantation, which indicates that the nanostructured titanium implants stimulated bone growth and accelerated formation of the bone-implant interface. During the early healing period, various environmental factors, such as occlusal forces, bacteria, and fibrous tissues, are capable of impairing interfacial formation and decreasing implant success due to the instability of the bone-implant interface. ${ }^{32,33}$ These results suggested that nanostructured implants may shorten the healing period and decrease the risk of implant failure. However, the shear strength of microporous titanium did not appear to be any different 
from that at 12 weeks post implantation. It is presumed that bone tissues can grow into the micropores of microporous titanium and form a micro-interlock, ${ }^{5}$ which greatly enhances bone-implant interfacial mechanical bonding. In summary, nanotopology is proven to have beneficial effects on the osteoblast response and bone growth.

\section{Conclusion}

It was shown that $\mathrm{TiO}_{2}$ nanotube arrays induced cell proliferation, alkaline phosphatase activity, and expression of osteogenic proteins to a greater extent than could microporous surfaces created by the acid etching method. Our in vivo study results also verify that nanostructured implants are beneficial for cell proliferation, osteogenic protein expression, and capillary proliferation in peri-implant tissues. Nanostructured implants also greatly increased the bone-implant interfacial strength in the early healing period after implantation. We believe that application of nanotopography on implant surfaces is feasible in clinical practice. It is anticipated that nanotube modification may contribute significantly to the design of efficient implant materials, although the effects of topology should be fully considered.

\section{Acknowledgments}

This study was supported by a grant from the National Natural Science Foundation of China (Grant no. 50871093), National Basic Research Program of China (973 Program, 2012CB933602), Postdoctoral Science Foundation of China (Grant no. 20110491738), and Project of Science and Technology Department of Jiangsu Province (Grant no. BK2010530).

\section{Disclosure}

The authors report no conflicts of interest in this work.

\section{References}

1. Satomi K, Alagawa Y, Nikai H, Tsuru H. Bone-implant interface structures after nontapping and tapping insertion of screw-type titanium alloy endosseous implants. J Prosthet Dent. 1988;59:339-342.

2. Schmidt C, Kaspar D, Sarkar MR, Claes LE, Ignatius AA. A scanning electron microscopy study of human osteoblast morphology on five orthopedic metals. J Biomed Mater Res. 2002;63:252-261.

3. Vlacic-Zischke J, Hamlet SM, Friis T, Tonetti MS, Ivanovski S. The influence of surface microroughness and hydrophilicity of titanium on the up-regulation of TGF $\beta /$ BMP signalling in osteoblasts. Biomaterials. 2011;32:665-671.

4. Wennerberg A, Hallgren C, Johansson C, Danelli S. A histomorphometric evaluation of screw-shaped implants each prepared with two surface roughnesses. Clin Oral Implants Res. 1998;9:11-19.

5. Otsuki B, Takemoto M, Fujibayashi S, Neo M, Kokubo T, Nakamura T. Pore throat size and connectivity determine bone and tissue ingrowth into porous implants: Three-dimensional micro-CT based structural analyses of porous bioactive titanium implants. Biomaterials. 2006;27: 5892-5900.
6. Wu C, Ramaswamy Y, Liu X, Wang G, Zreiqat H. Plasma-sprayed CaTiSiO5 ceramic coating on Ti-6Al-4V with excellent bonding strength, stability and cellular bioactivity. $J R$ Soc Interface. 2009;6: 159-168.

7. Liu X, Morra M, Carpi A, Li B. Bioactive calcium silicate ceramics and coatings. Biomed Pharmacother. 2008;62:526-529.

8. Liu DL, Feng B, Lu X, Chen JM. Titanium oxide nanotubes with large diameters fabricated by two-step anodic oxidation. Rare Metal Materials and Engineering. 2010;39:325-328.

9. Oh S, Brammer KS, Li YS, et al. Stem cell fate dictated solely by altered nanotube dimension. Proc Natl Acad Sci U S A. 2009;106:2130-2135.

10. Mendonça G, Mendonça DB, Simões LG, et al. The effects of implant surface nanoscale features on osteoblast-specific gene expression. Biomaterials. 2009;30:4053-4062.

11. Anselme K, Bigerelle M, Loison I, Noël B, Hardouin P. Kinetic study of the expression of $\beta$-catenin, actin and vinculin during osteoblastic adhesion on grooved titanium substrates. Biomed Mater Eng. 2004;14:545-556.

12. Webster TJ, Ejiofor JU. Increased osteoblast adhesion on nanophase metals: $\mathrm{Ti}, \mathrm{Ti}_{6} \mathrm{Al}_{4} \mathrm{~V}$, and CoCrMo. Biomaterials. 2004;25:4731-4739.

13. Balaur E, Macak JM, Taveira L, Schmuki P. Tailoring the wettability of $\mathrm{TiO}_{2}$ nanotube layers. Electrochem Commun. 2005;7:1066-1070.

14. Balaur E, Macak JM, Tsuchiya H, Schmuki P. Wetting behaviour of layers of $\mathrm{TiO}_{2}$ nanotubes with different diameters. $J$ Mater Chem. 2005; $15: 4488-4491$.

15. Redey SA, Nardin M, Bernache-Assolant D, et al. Behavior of human osteoblastic cells on stoichiometric hydroxyapatite and type A carbonate apatite: role of surface energy. J Biomed Mater Res. 2000;50:353-364.

16. Zhao G, Schwartz Z, Wieland M, et al. High surface energy enhances cell response to titanium substrate microstructure. J Biomed Mater Res A. 2005;74:49-58.

17. Feng B, Weng J, Yang BC, Qu SX, Zhang XD. Characterization of surface oxide films on titanium and adhesion of osteoblast. Biomaterials. 2003;24:4663-4670.

18. Kim HW, Knowles JC, Salih V, Kim HE. Hydroxyapatite and fluorhydroxyapatite layered film on titanium processed by a sol-gel route for hard-tissue implants. J Biomed Mater Res B Appl Biomater. 2004;71:66-76.

19. Oh S, Daraio C, Chen LH, Pisanic TR, Fiñones RR, Jin S. Significantly accelerated osteoblast cell growth on aligned $\mathrm{TiO}_{2}$ nanotubes. J Biomed Mater Res A. 2006;78:97-103.

20. Lohmann CH, Bonewald LF, Sisk MA, et al. Maturation state determines the response of osteogenic cells to surface roughness and 1,25dihydroxy vitamin D3. J Bone Miner Res. 2000;15:1169-1180.

21. Boyan BD, Lossdörfer S, Wang L, et al. Osteoblasts generate an osteogenic microenvironment when grown on surfaces with rough microtopographies. Eur Cell Mater. 2003;6:22-27.

22. Gleiche M, Chi LF, Fuchs H. Nanoscopic channel lattices with controlled anisotropic wetting. Nature. 2000;403:173-175.

23. Lenhert S, Meier MB, Meyer U, Chi L, Wiesmann HP. Osteoblast alignment, elongation and migration on grooved polystyrene surfaces patterned by Langmuir-Blodgett lithography. Biomaterials. 2005;26:563-570.

24. Gao L, Feng B, Wang J, et al. Micro/nanostructural porous surface on titanium and bioactivity. J Biomed Mater Res B Appl Biomater. 2009;89B:335-341.

25. Mustafa K, Wennerberg A, Wroblewski J, Hultenby K, Lopez BS, Arvidson K. Determining optimal surface roughness of $\mathrm{TiO}_{2}$ blasted titanium implant material for attachment, proliferation and differentiation of cells derived from human mandibular alveolar bone. Clin Oral Implants Res. 2001;12:515-525.

26. Mustafa K, Wroblewski J, Hultenby K, Lopez BS, Arvidson K. Effects of titanium surfaces blasted with $\mathrm{TiO}_{2}$ particles on the initial attachment of cells derived from human mandibular bone. A scanning electron microscopic and histomorphometric analysis. Clin Oral Implants Res. 2000;11:116-128. 
27. Gori F, Hofbauer LC, Dunstan CR, Spelsberg TC, Khosla S, Riggs BL. The expression of osteoprotegerin and RANK ligand and the support of osteoclast formation by stromal-osteoblast lineage cells is developmentally regulated. Endocrinology. 2000;141:4768-4776.

28. Leach JK, Kaigler D, Wang Z, Krebsbach PH, Mooney DJ. Coating of VEGF-releasing scaffolds with bioactive glass for angiogenesis and bone regeneration. Biomaterials. 2006;27:3249-3255.

29. Johansson CB, Han CH, Wennerberg A, Albrektsson T. A quantitative comparison of machined commercially pure titanium and titaniumaluminum-vanadium implants in rabbit bone. Int J Oral Maxillofac Implants. 1998;13:315-321.

30. Rüger M, Gensior TJ, Herren C, et al. The removal of $\mathrm{Al}_{2} \mathrm{O}_{3}$ particles from grit-blasted titanium implant surfaces: effects on biocompatibility, osseointegration and interface strength in vivo. Acta Biomater. 2010;6:2852-2861.
31. Castellani C, Lindtner RA, Hausbrandt $P$, et al. Bone-implant interface strength and osseointegration: Biodegradable magnesium alloy versus standard titanium control. Acta Biomater. 2011;7:432-440.

32. Natali AN, Carniel EL, Pavan PG. Investigation of viscoelastoplastic response of bone tissue in oral implants press fit process. $J$ Biomed Mater Res B Appl Biomater. 2009;91:868-875.

33. Degidi M, Iezzi G, Perrotti V, Piattelli A. Comparative analysis of immediate functional loading and immediate nonfunctional loading to traditional healing periods: a 5-year follow-up of 550 dental implants. Clin Implant Dent Relat Res. 2009;11:257-266.
International Journal of Nanomedicine

\section{Publish your work in this journal}

The International Journal of Nanomedicine is an international, peerreviewed journal focusing on the application of nanotechnology in diagnostics, therapeutics, and drug delivery systems throughout the biomedical field. This journal is indexed on PubMed Central,

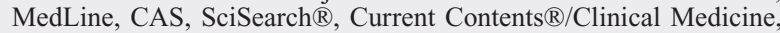

\section{Dovepress}

Journal Citation Reports/Science Edition, EMBase, Scopus and the Elsevier Bibliographic databases. The manuscript management system is completely online and includes a very quick and fair peer-review system, which is all easy to use. Visit http://www.dovepress.com/ testimonials.php to read real quotes from published authors.

Submit your manuscript here: http://www.dovepress.com/international-journal-of-nanomedicine-journal 